\title{
O desenvolvimento da compreensão do tempo e do tempo histórica nas crianças: um estudo de caso com alunos portugueses de primária $\left(1{ }^{\circ} \mathrm{CEB}\right)^{1}$
}

The development of children's understanding of time and historical time: a case study with Portuguese primary students

\author{
Glória SOLÉ2 \\ gsole@ie.uminho.pt \\ Universidade do Minho, Portugal
}

\begin{abstract}
Resumen:
La investigación en educación histórica ha demostrado que la comprensión del tiempo es crucial para la comprensión histórica y el tiempo histórico. Sin embargo, el enfoque sobre el desarrollo de la comprensión histórica y temporal por los niños ha sido en las últimas décadas un área de investigación bastante controvertida. Este artículo presenta, en una primera parte, una revisión de literatura extensa y actualizada relacionada con la enseñanza de la historia que tiende a evidenciar la relevancia de la importancia de la comprensión temporal y de conceptos de tiempo para el desarrollo del pensamiento histórico
\end{abstract}

1 Este trabalho é financiado pelo CIEd - Centro de Investigação em Educação, projetos UID/CED/1661/2013 e UID/CED/1661/2016, Instituto de Educação, Universidade do Minho, através de fundos nacionais da FCT/MCTES-PT.

2 Dirección para correspondencia (correspondence address):

Glória Solé. CIEd/Universidade do Minho/Instituto de Educação. Travessa da Presa n. ${ }^{\circ}$ 18, Meadela, Viana do Castelo. 4900-790- Viana do Castelo (Portugal). 
O desenvolvimento da compreensão do tempo e do tempo histórica nas crianças: um estudo de caso com alunos portugueses de primária (1. $\left.{ }^{\circ} \mathrm{CEB}\right)$

GLÓRIA SOLÉ

de um estudo de caso, longitudinal e interpretativo, sobre a compreensão do tempo histórico pelas crianças do ensino primário. A pesquisa envolveu duas turmas (1..$^{\circ}$ ano- 24 alunos, com idade de 6-7 anos e do $3 .^{\circ}$ ano- 25 alunos, com idade de 8-9 anos) de alunos do ensino primário $\left(1 .{ }^{\circ} \mathrm{CEB}\right)$, acompanhadas durante dois anos letivos, numa escola primária (1. ${ }^{\circ}$ Ciclo do Ensino Básico) urbana, no norte de Portugal. Em três momentos durante o estudo, no início e no final dos anos letivos, os alunos realizaram uma tarefa de ordenação de 6/7 imagens relacionadas com famílias de várias épocas, explicando a sua ordenação. Para a recolha de dados aplicou-se uma entrevista semiestrutura para identificar mudanças nas explicações dadas e na compreensão do tempo histórico antes e após um ano de intervenção.Os resultados evidenciam um desenvolvimento de competências temporais, ao nível cronológico e uma complexificação do raciocínio temporal, assim como alterações nas suas conceções sobre mudança.

\section{Palavras-chave:}

Educação histórica; compreensão temporal; cronologia; competências históricas. en los niños.En una segunda parte, presenta los resultados de un estudio de caso, longitudinal e interpretativo, sobre la comprensión del tiempo histórico por los niños de la enseñanza primaria. La investigación involucró dos grupos (1. ${ }^{\circ}$ año-24 alumnos, con edad de 6-7 años y del $3^{\circ}$ año-25 alumnos, con edad de 8-9 años) de la enseñanza primaria, acompañadas durante dos años lectivos, en una escuela primaria urbana, en el norte de Portugal.En tres momentos durante el estudio, al inicio y al final de los años lectivos, los alumnos realizaron una tarea de ordenación de 6/7 imágenes relacionadas con familias de varias épocas.Para la recogida de datos se aplicó una entrevista semi-estructurada para identificar cambios en las explicaciones dadas y en la comprensión del tiempo histórico antes y después de un año de intervención. Los resultados evidencian un desarrollo de competencias temporales, a nivel cronológico y una complejidad del raciocinio temporal, así como cambios en sus concepciones sobre cambio.

\section{Palabras clave:}

Educación histórica; comprensión temporal; cronología; competencias históricas.

\begin{abstract}
:
Research in History Education has shown that understanding time is crucial to understand historical thinking and historical time. However, in recent decades the approach to the development of historical and temporal understandings of time by children has been a very controversial area of research. This article presents, in a first part, an extensive and updated literature review related to history teaching that tends to highlight the relevance of temporal understanding and time concepts for the development of children's historical thinking. The second part reports the findings of a longitudinal and interpretative case study with primary school children's understanding of time and historical time. The research involved two classes of primary school students (1st grade with 24 students aged 6-7 and 3rd grade with 25 students aged 8-9) during two school academic years in an urban primary school in Northern Portugal. At three different times during the study the students were asked to arrange historical pictures (about families) in chronological order and explain their arrangements. For data collection a semi-structured interview was applied to identify changes in the explanations given by students and in the understanding of historical time before and after one year of instructional intervention. The results show the students improved their temporal competences at a chronological level, their temporal reasoning and also their understanding of the idea of change.
\end{abstract}

Keywords:

History education; temporal understanding; chronology; historical competences. 
Fecha de recepción: 2-10-2017

Fecha de aceptación: 22-12-2017

\section{Introdução}

Este artigo procura estabelecer a ligação entre conceitos de tempo, tempo histórico e compreensão temporal relacionados com a aprendizagem de história pelas crianças.A investigação em Educação Histórica tem demonstrado que a compreensão do tempo é crucial para a compreensão histórica e do tempo histórico. Contudo, a abordagem sobre o desenvolvimento da compreensão histórica e temporal pelas crianças foi nas últimas décadas uma área de investigação bastante controversa na investigação em educação.

Os estudos pioneiros sobre a aprendizagem do tempo pelas crianças surgem associados a investigações na área da psicologia, da matemática e da linguística e só mais tarde a partir dos anos 70 e 80 é que surgem novas perspetivas investigativas na área da educação.

Uma das áreas de investigação da aprendizagem do tempo está associada à aprendizagem do tempo físico pelas crianças, enfatizando como as crianças percebem a duração e a velocidade do tempo. A literatura nesta área baseia-se no trabalho pioneiro realizado por Piaget (1946) e dos seus seguidores (Fraisse, 1982; Friedman, 1982). Estas investigações incidem sobre o desenvolvimento de conceitos de tempo e desenvolvimento cognitivo em geral. As investigações sobre como as crianças pensam e aprendem foram durante muito tempo dominadas pelas teorias de Piaget, que enfatizavam o desenvolvimento cognitivo pelos três estádios de desenvolvimento, sequenciais e invariantes. Na década de 60 e 70, influenciados pelas teorias Piagetianas, vários estudos sugerem que a compreensão do tempo e da história estão diretamente relacionados com o desenvolvimento cognitivo, e que os conceitos temporais e históricos se desenvolvem conjuntamente (Jahoda, 1963; Hallam, 1967, 1979; Peel,1971; Sleeper,1975).Estas investigações procuravam identificar os estádios de desenvolvimento piagetianos no desenvolvimento da compreensão histórica dos alunos.Esta linha de investigação teve claros reflexos no ensino da História, assistindo-se nos anos 70 a um movimento contra o ensino de história nos primeiros anos de escolaridade e nos curricula, por advogarem que as crianças não tem 
capacidade de abstração, e por isso não serem capazes de compreender certos conceitos como o de causalidade histórica, nem serem capazes de pensar historicamente,e por isso não poderiam aprender história antes dos 16 anos.

A partir dos anos 70 e 80 o ensino da história mereceu a atenção de vários investigadores em especial do Reino Unido e dos Estados Unidos da América. Estas investigações, que se basearam nas ideias de Bruner (1960) e de Vygotsky (1962), levaram a recolocar o problema da capacidade ou incapacidade do estudo da história por crianças e adolescentes e os contextos para a sua aprendizagem. O contributo da investigação anglo-saxónica realizada desde a década de 70, desenvolvida nos anos 80 e 90 especialmente em dois grupos de investigação, um em Londres no Instituto de Educação e outro em Leeds, liderados respetivamente por Peter Lee e Daniel Shemilt contribuiu para a afirmação da Educação Histórica como área epistemológica (Ashby \&Lee, 1987; Lee \& Ashby, 1987; Shemilt, 1980, 1987).

Estudos realizados também nos E.U.A (Downey \& Levstik 1991; Levstik \& Papas, 1987, 1992; Thornton \& Vukelich, 1988) e Canadá e um pouco mais recentemente a partir dos anos 90 em outros países, como Portugal, Espanha, Brasil, Holanda, Grécia, África do Sul, entre outros, seguem esta mesma linha de investigação em cognição histórica, que se preocupa em estudar como os alunos aprendem história, compreendem a história e pensam historicamente.

Este estudo que aqui se apresenta insere-se nesta linha de investigação em cognição histórica que defende que é possível as crianças aprenderem história, desenvolver a compreensão temporal e histórica, utilizando-se estratégias adequadas.Assim, na primeira parte deste texto analisa-se o conceito de tempo e de tempo histórico segundo diferentes perspetivas, pois este conceito não é consensual.Na segunda parte procede-se a uma revisão de literatura atualizada sobre a compreensão do tempo e do tempo histórico pelas crianças. A terceira parte apresenta parte do estudo realizado no âmbito do meu doutoramento (Solé, 2009) que procura analisar a compreensão do tempo pelas crianças e os contextos para o seu desenvolvimento. $\mathrm{O}$ artigo termina com algumas conclusões deste estudo, em articulação com os vários estudos de investigação subordinados a esta temática, sobre a aprendizagem de conceitos de tempo, tempo histórico e compreensão histórica pelas crianças. 


\section{Tempo e tempo histórico}

É consensual para os investigadores em Educação Histórica que compreender o tempo é essencial para o estudo da história. Porque toda a história envolve o uso do passado para entender o presente, pois é importante dar sentido ao conteúdo da história e localizá-lo com referência ao presente.

A definição de tempo inclui uma variedade de conceitos. Estamos constantemente envolvidos por diferentes formas de tempo que estão inter-relacionadas entre si: tempo pessoal, tempo físico, tempo psicológico e tempo histórico. O tempo é uma construção do homem e foi criado para nos permitir estruturar as nossas vidas na sociedade, são construções múltiplas e paralelas, não uma única entidade, mas com" níveis de compreensão que se baseiam nos anteriores" (Barton, 2008, p. 63).O tempo físico é mensurável em horas, dias, meses, anos e séculos. É algo que não se vê, é imaterial, o que o torna difícil de apreender e que se adquire pela aprendizagem, ao contrário do espaço que é visível. A sociedade foi construindo instrumentos que permitem que o tempo seja comum a todos, inventou para isso, o relógio, o calendário, a cronologia, tornando o tempo objetivo e quantificável.

Vários investigadores enfatizam a importância de adquirir noções temporais para melhorar a compreensão histórica. (Asensio, Carretero e Pozo, 1989; Friedman, 1982; Jahoda, 1963; Montangero, 1984; Thornton \& Vukelich, 1988).Sobre o conceito de tempo, Jahoda (1963) considera que "o tempo não é um fluxo uniforme e homogéneo, mas vinculado a objetos, locais ou acontecimentos" (pág. 90).Sendo um conceito complexo e heterogéneo, este integra vários conceitos temporais articulados entre si, nomeadamente, segundo Friedman (1982): a) a ordem temporal da sucessão, que permite organizar de forma sequencial os elementos de um sistema que liga o conceito de número (número ordinal são elementos das horas do relógio e datas do calendário); b) o intervalo ou duração de cada elemento do sistema ou a totalidade da sequência; c) a ideia de ciclo que inclui a ordem e a recorrência. Outros autores propõem uma interpretação compreensiva das noções temporais, sendo estas concebidas como um conjunto de subsistemas que funcionam de forma inter-relacional (Asensio, Carretero e Pozo, 1989; Montagero,1984; Pagès \& Santisteban, 2010; Wilschut, 2010). Thornton \& Vukelich (1988) procuraram explicar a relação entre 
aprendizagem do tempo e a aprendizagem da história. Começam por definir os três tipos de tempo, o tempo do relógio, o do calendário e o tempo histórico. Consideram que a aprendizagem de conceitos de tempo e de cronologia são pré-requisitos para a aprendizagem e compreensão da história. Para os autores a compreensão do tempo pelos mais novos está associada ao seu desenvolvimento cognitivo, reconhecendo no entanto, a importância da instrução para o seu desenvolvimento.

O conceito de tempo histórico não é consensual, podendo ter significados diferentes para várias pessoas e culturas. Este tempo pode ser medido de forma objetiva através da cronologia e entendido de forma relativa porque depende da experiência de cada cultura, podendo ser variável e heterogéneo (Domínguez 2015, Sacristán 2012, Solé 2009). Segundo Harris (1976 citado por Hodkinson, 2003) o tempo histórico está relacionado com três áreas conceptuais: cronologia (sequencialização); duração e passagem do tempo e medição do tempo. Stow e Haydn (2004) afirmam que a capacidade em sequencializar acontecimentos, calcular o tempo ou períodos de tempo, são um meio para promover e desenvolver as estruturas mentais em relação ao desenvolvimento e compreensão temporal afirmando que "[a] cronologia na sala de aula pode contribuir para aumentar o desenvolvimento e a compreensão do tempo histórico (p. 88) ".Vários autores relacionam o tempo histórico com a compreensão cronológica (datar, sequencializar datas, acontecimentos, personalidades), entre outros fatores indicam também, a compreensão de épocas, a relação passado e presente e a utilização de linguagem temporal (Asensio, Carretero e Pozo, 1989; Wood, 1995, Oakden \& Sturt, 1922). O tempo histórico é um meta conceito, ou um conceito de ordem superior que engloba e inclui uma grande diversidade de conceitos ou noções temporais" (Asensio, Carretero \& Pozo, 1989,p. 115).É por isso um conceito inclusivo que integra vários conceitos temporais, o que faz com que "este entrelaçado conceptual é o conteúdo constitutivo da disciplina e tem portanto uma entidade formal e abstrata" (Asensio, Carretero \& Pozo, 1989, p. 115).

Embora o conceito de tempo histórico não se limita apenas à cronologia como defendem vários autores, este conceito tem um lugar controverso nos debates sobre os métodos de ensino da história, mas ocupa um lugar central no desenvolvimento da compreensão histórica das crianças (Hodkinson, 2003; Stow e Haydn, 2004; Solé, 2009;Hernández \& Paz, 2013). A capacidade de sequencializar objetos por uma ordem 
cronológica é defendida por vários investigadores como essencial para a compreensão temporal e histórica (Forrest \&Harnett, 1996; Stow \& Haydn 2004; Wood, 1995).

Podemos afirmar que o estudo do tempo histórico pressupõe também a interligação entre passado, presente e futuro, essencial para a formação e desenvolvimento da consciência histórica, que implica que sejamos capazes de interpretar o passado, mas também que possamos utilizar esse conhecimento para compreender o presente e perspetivar o futuro (Rüsen, 2007; Groot-Reuvekamp et al. 2014). A aprendizagem histórica, entendida como "um processo mental de adquirir competências históricas através do processamento da experiência da mudança temporal do mundo humano no passado" (Rüsen, 2016, p. 26), torna-se muito relevante, uma vez que permite uma compreensão intergeracional da vida e o desenvolvimento de cidadãos críticos e interventivos na sociedade atual (Pagès \& Santisteban 2010), em que a consciência histórica e a orientação temporal (Barca, 2015) têm um papel importante na aprendizagem da história.

\section{A compreensão do tempo e do tempo histórico pelas crianças}

O tempo é um conceito complexo como explicitamos anteriormente, que abarca uma diversidade de conceções e formas. Estamos constantemente envolvidos por diferentes formas de tempo, inter-relacionadas umas com as outras: o tempo pessoal: o tempo físico (matemático/quantificável); tempo social; o tempo psicológico e o tempo histórico (Solé, 2009).

A revisão de literatura sobre investigação relacionada com aprendizagem de história pelas crianças ajuda a perceber como as crianças compreendem a história e destacam neste processo de aprendizagem a relevância da compreensão do tempo e do tempo histórico no desenvolvimento do pensamento e compreensão histórica (Downey \& Levstik, 1991; Wineburg, 1996). Algumas sínteses de revisão de literatura sobre o ensino de história a crianças sugerem diferentes paradigmas acerca da compreensão de conceitos de tempo pelas crianças e a sua articulação com a compreensão histórica (Thornton \& Vukelich, 1988; Stow \& Haydn, 2004). Em vários estudos veicula-se que a aprendizagem do tempo não é fácil para as crianças e que esta é uma componente importante para a compreensão histórica integrando 
uma variedade de áreas de compreensão, incluindo a matemática, a linguística e a lógica (Stow \& Haydn, 2004).

Vários investigadores sustentam que competências matemáticas são relevantes para o desenvolvimento de conceitos de tempo (Friedman, 1982, Lomas, 1990), afirmando que a compreensão temporal está diretamente relacionada com o desenvolvimento do raciocínio matemático. Em contrapartida, para Hodkinson (2003), a aptidão matemática em geral, por si só, não é o fator determinante na assimilação da cognição temporal, asseverando não existir uma relação direta entre a influência da matemática e o desenvolvimento de conceitos chave de tempo histórico, nas crianças como, por exemplo, o de duração.

Para outros investigadores a linguagem tem um papel central na aquisição, desenvolvimento e compreensão do tempo. A linguagem de tempo, por ser considerada, como um potente símbolo da compreensão do tempo pelas crianças, recebeu uma maior atenção por parte dos investigadores (Stow \& Haydn, 2004). Consideram que capacidade linguística é um fator determinante para a compreensão temporal. Segundo West (1981), o desenvolvimento da aprendizagem do tempo está diretamente associado com a proficiência na linguagem, sendo esta aprendizagem difícil para as crianças, isto porque existem diferentes sistemas para descrever o tempo. Esta aprendizagem do tempo faz-se de forma gradual e progressiva em contexto escolar à medida que a criança progride na escola (Pagès \& Santisteban, 2010). Muitos investigadores constatam que as crianças são capazes de realizar sequências temporais (através da ordenação de imagens), mas muitas vezes não sabem explicar o porquê dessa ordenação por dificuldades de se exprimir verbalmente (Barton \& Levstik, 1996; Barton, 2001; Barton, 2002; Foster, Hoge \& Rosch, 1999; Hoge \& Foster, 2002; Harnett, 1993; Levstik \& Papas, 1987; Machado, 2005; Solé, 2009; West, 1991). Segundo Harner (1982) as estruturas linguísticas parecem poder afetar o processo psicológico que está envolvido na conceptualização do passado e do futuro. Para Cooper (1995) a linguagem surge como um instrumento para aceder ao passado com o qual as crianças podem refinar conceitos. Refere que é preciso estimular as crianças a utilizar linguagem e vocabulário de tempo, pois aprender sobre o passado pressupõe adquirir vocabulário, que, até certo ponto, é específico da história.

Vários investigadores constataram que um dos problemas no ensino de conceitos de tempo está relacionado com a linguagem, considerando que 
a linguagem relacionada com tempo é pouco familiar às crianças, quer ao nível do tempo dos verbos, quer com termos como a,.C., d. C., era, geração, ano, década, século, período e termos como progresso e regressão.

Parece evidente a ideia de que a linguagem pode afetar a compreensão e a capacidade das crianças desenvolverem conceitos de tempo. Vários autores sugerem também que o contexto cultural e educacional pode influenciar a velocidade do desenvolvimento da linguagem de tempo nas crianças (Cooper, 1991; 1995; Barton, 2001; 2002; Groot-Reuvekamp et. al 2014; Hodkinson, 2003; Patriarca \& Alleman, 1987; Solé, 2009; Sacristán, 2012; Thornton \& Vukelich, 1988).

As várias investigações relacionadas com a compreensão temporal tendem a destacar que a aprendizagem de conceitos de tempo é vital e importante no ensino da história desde os primeiros anos de escolaridade, tornando-se esta essencial para a compreensão histórica e inerentemente para a compreensão do tempo histórico.

\section{Estudo empírico}

\section{Metodologia e procedimentos de investigação}

Este estudo é uma parte da investigação realizada em tese de doutoramento intitulada: "O ensino da História no $1 .^{\circ}$ Ciclo: a concepção do tempo histórico nas crianças e os contextos para o seu desenvolvimento" (Solé, 2009), realizado com alunos do 1. ${ }^{\circ}$ CEB (6-10 anos) numa escola do norte de Portugal. O estudo foi realizado em duas turmas, uma no $1 \% 2^{\circ}$ ano (24 alunos) e a outra no $3 . \% .^{\circ}$ ano (25 alunos), ao longo de dois anos escolares. Esta investigação insere-se no quadro da investigação de natureza interpretativa, é predominantemente qualitativa (Erickson, 1986) e pode-se considerar um estudo de caso longitudinal (Yin, 2003), pois descreve o processo de aprendizagem e de compreensão do tempo histórico das crianças do $1 .^{\circ}$ ao $4 .^{\circ}$ ano de escolaridade, de dois grupos turma durante dois anos. Este estudo constou de duas partes relativamente autónomas mas com objetivos comuns, a realização de entrevistas a alunos do $1 .^{\circ}$ e $3 .^{\circ}$ anos do CEB no início e final do ano letivo e intervenções (atividades) realizadas e implementadas pela investigadora na sala de aula usando estratégias apropriadas para o ensino de Estudos Sociais/História. 
Este artigo descreve apenas parte dos resultados deste estudo, realizado com base nas entrevistas semi-estruturadas, realizadas ao longo dos dois anos do estudo. Cada aluno (24 no $1 .{ }^{\circ} / 2 .^{\circ}$ ano e 25 no $3 . \% / 4 .{ }^{\circ}$ ano) foi entrevistado três vezes: no início e no final do $1 .^{\circ}$ e $3 .^{\circ}$ ano e no fim do $2 .^{\circ}$ e $4 .^{\circ}$ anos. Através das entrevistas, procurámos averiguar nestes alunos mudanças na compreensão temporal e a eventual evolução/mudança das conceções de tempo histórico e do conceito de mudança, após dois anos de intervenção na sala de aula.

As questões da entrevista semi-estruturada aplicadas neste estudo, inspiram-se no estudo realizado por Levstik \& Barton (1996) e Barton \& Levstik (1996) e Hoge \& Foster (2002). A entrevista girou à volta da sequencialização de uma série de imagens e das justificações para a sua sequencialização para perceber a conceção de tempo histórico e de mudança veiculada por estes alunos (anexo A). A investigadora foi colocando questões tais como: "Qual é a mais antiga e a mais recente? Porque puseste esta antes e esta depois? O que te levou a pensar que esta é mais antiga do que esta?. Entre outras que não iremos aqui tratar neste artigo, relacionadas com o que entendem por história, passado e a finalidade da história.

Para as entrevistas foram selecionadas imagens referentes a diferentes contextos e épocas históricas sobre a vida familiar que achámos que qualquer adulto seria capaz de sequencializar de forma correta, seis para o $1 .^{\circ}$ e $2 .^{\circ}$ ano de escolaridade e sete para o $3 .^{\circ}$ e $4 .^{\circ}$ ano (acrescentou-se para este alunos a imagem C). As imagens representam cenas familiares desde a Pré-História até à atualidade. Apresentamos a lista das imagens, com uma breve descrição do seu conteúdo e a data de cada uma delas.

A- Desenho de uma família da Pré-História, numa caverna, à volta de uma fogueira. Retirada da Enciclopédia da Humanidade, (1990, p. 69), +-10 000 a.C.

B- Iluminura com uma família à mesa, servida por um escravo. Livro de Horas de D. Manuel, atribuída a António de Holanda, c. 15171538, Museu Nacional de Arte Antiga.

C- Retrato da família do $1 .^{\circ}$ Visconde de Santarém num dos salões da sua residência com a esposa e os cinco filhos. Pintura de Domingos Sequeira, 1816, Museu Nacional de Arte Antiga.

D- (imagem C para o $1 .^{\circ}$ e $2 .^{\circ}$ anos) - Pintura de uma família burguesa junto à lareira, com empregada, Avant le bal de E. Debat-Ponsan, 1886, Museé des Beaux Arts de Tours. 
E- (imagem D para o $1 .^{\circ}$ e $2 .^{\circ}$ anos)- Cartaz de propaganda do Estado Novo com família rural, 1933-49, Biblioteca Nacional.

F- (imagem E para o $1 .^{\circ}$ e $2 .^{\circ}$ anos) - Família dos atuais duques de Bragança em sua casa, 1999.

G- (imagem $\mathrm{F}$ para o $1 .^{\circ}$ e $2 .^{\circ}$ anos) - Família dos atuais duques de Bragança, 2003.

Na seleção das imagens, procurou-se abarcar uma distância temporal grande para verificar em que medida os alunos são capazes de sequencializar as imagens independentemente de conhecerem e identificarem diferentes períodos históricos, todas circunscritas a uma mesma temática, a família ao longo dos tempos.

Quanto à implementação da entrevista, esta foi realizada individualmente e áudio gravada. As imagens foram apresentadas todas ao mesmo tempo para as ordenarem e justificarem a sua sequencialização. As entrevistas foram transcritas pela própria investigadora, analisadas e categorizadas. O sistema de categorização das entrevistas inspirou-se no modelo de categorização do estudo realizado por Levstik \& Barton (1996), Barton \& Levstik (1996) e Barton (2001), partindo das questões de investigação e da análise de conteúdo das respostas dos alunos tendo por base o modelo de análise indutiva da Grounded Theory (Strauss \& Corbin, 1990). Como suporte informático recorremos ao NVivo 2.0, software usado na investigação qualitativa (Using NVivo in Qualitative Research).

\section{Análise e discussão dos resultados}

$\mathrm{Na}$ análise das entrevistas privilegiamos como estratégia uma análise holística e indutiva das repostas dos alunos às perguntas. No processo de codificação elaboramos várias tabelas e grelhas para comparar as respostas dos alunos e melhor identificar padrões comuns de resposta, o que facilitou posteriormente a construção de um sistema de categorização.

A análise dos dados do estudo permitiu definir um conjunto de parâmetros sobre a compreensão histórica e temporal dos alunos associada ao processo de ordenação de várias imagens e justificação dessa ordenação.Identificamos três tipos de parâmetros que integram um conjunto de categorias e sub-categorias:

1. Ordenação cronológica das imagens 
O desenvolvimento da compreensão do tempo e do tempo histórica nas crianças: um estudo de caso com alunos portugueses de primária (1. $\left.{ }^{\circ} \mathrm{CEB}\right)$

GLÓRIA SOLÉ

2. Processos e estratégias utilizados na sequencialização de imagens

3. Ideias sobre a mudança histórica

\section{ORDENAÇÃO CRONOLÓGICA DAS IMAGENS}

Começamos por analisar a ordenação cronológica das imagens colocadas pelos alunos, o que nos permitiu identificar diferentes tipologias de ordenação, evidenciando-se a persistência ou alteração das tipologias apresentadas por cada aluno ao longo dos dois anos do estudo. A análise da colocação das imagens na ordem cronológica permitiu-nos inferir de forma clara quais as imagens que apresentam outra ordem e as possíveis explicações para isso.

Constatámos que é no início do $1 .^{\circ}$ ano que se verifica uma maior diversidade de tipologias de ordenação de imagens (10 tipologias), passando no final do ano apenas a quatro tipologias (1, 2, 5 e 10) e no final do $2 .^{\circ}$ ano apenas a três tipologias $(1,2$ e 3$)$, as mais corretas. No conjunto das três entrevistas a ordenação mais proposta foi a tipologia 1 (ABCDEF), a correta, seguida pela tipologia 2 (ABDCEF).

Podemos constatar que os alunos do $3 .^{\circ}$ e 4 . anos tem um melhor desempenho na ordenação das imagens, apresentam um menor número de tipologias na ordenação cronológica das imagens do que os alunos do $1 .^{\circ}$ e $2 .^{\circ}$ anos, apesar de terem mais uma imagem (7 imagens), apresentando assim sete tipologias no início do $3 .^{\circ}$ ano, diminuindo para quatro tipologias no final do $4 .^{\circ}$ ano.

As maiores trocas de ordem das imagens concentraram-se entre a $3 .^{a}$ e a $4 .^{a}$ imagem, ou seja nas imagens do meio da sequência (C e D) (figura n. ${ }^{\circ} 1$ ). No $1 .^{\circ}$ ano foi evidente a melhoria do início para o final do ano, tendo 15 alunos colocado corretamente as imagens. No entanto, os resultados foram piores no final do $2 .^{\circ}$ ano $\left(3 .^{a}\right.$ entrevista), em que só oito as colocaram corretamente, tendo 13 alunos trocado as posições das imagens $\mathrm{C}$ e D e três as posições das imagens C, B e D.

Também os alunos do $3 .^{\circ}$ e $4 .^{\circ}$ anos foram menos assertivos nas imagens do meio da sequência, tendo-se revelado aqui as maiores trocas de ordem, ou seja nas imagens $\mathrm{C}, \mathrm{D}$ e $\mathrm{E}$, revelando estes maiores dificuldades em as sequencializar como se evidenciou através das justificações (Figura n. ${ }^{\circ}$ 2). No entanto, a partir do final do $3 .^{\circ}$ ano $\left(2 .^{a}\right.$ entrevista) mais de metade dos alunos colocou-as na posição correta. 


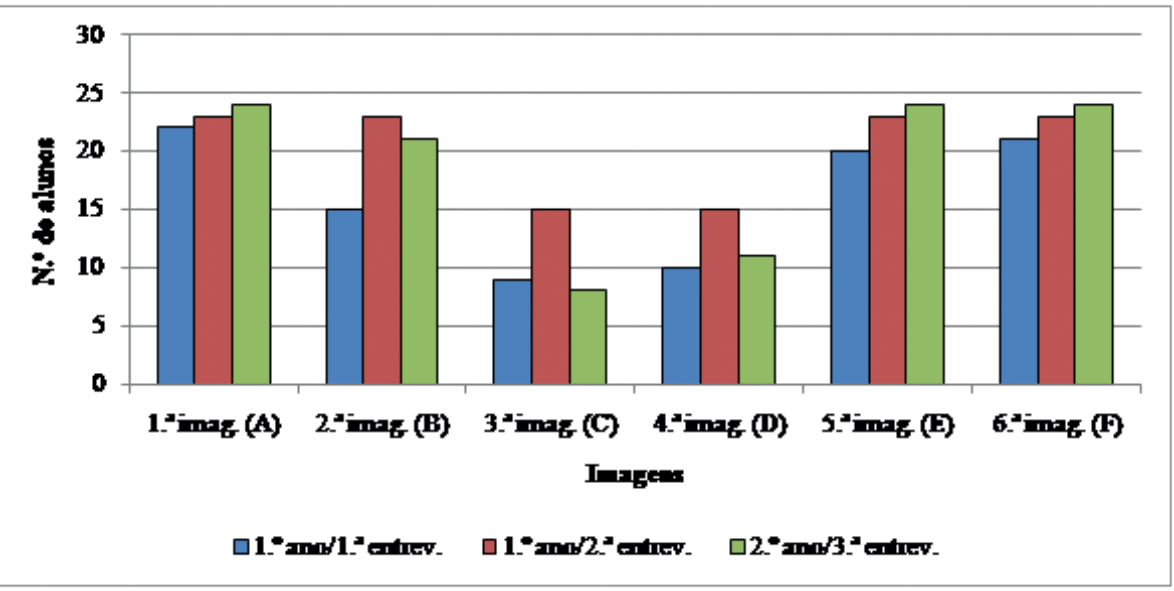

Figura 1. Gráfico- Colocação correta das imagens pelos alunos do $1 .^{\circ}$ ano $\left(1 .^{a}\right.$ e $2 .^{a}$ entrevista) e $2 .^{\circ}$ ano ( $3 .^{a}$ entrevista) (n.os absolutos)

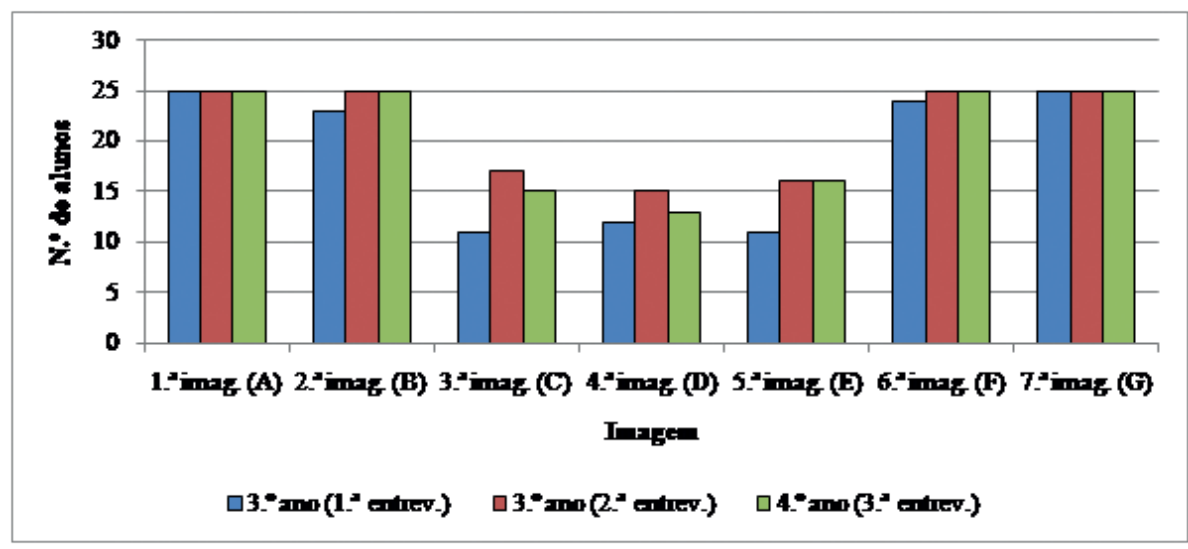

Figura 2. Gráfico- Colocação correta das imagens pelos alunos do $3 .^{\circ}$ ano (1. ${ }^{\mathrm{a}}$ e $2 .^{a}$ entrevistas) e $4 .^{\circ}$ ano (3. ${ }^{a}$ entrevista) (n.os absolutos)

Quanto à ordenação cronológica das imagens pudemos constatar pela análise empírica dos dados que os alunos ao longo dos dois anos revelaram uma melhor capacidade em sequencializar. Tal como noutros estudos (Barton \& Levstik, 1996 e Hoge \& Foster, 2002) também verificámos que foi nas imagens do meio da sequência que maiores trocas foram efetuadas, associadas à ideia dominante de progresso linear que os alunos manifestam principalmente os mais novos do $1 .^{\circ} \mathrm{e} 2 .^{\circ}$ anos, o que os levou a julgar a imagem do Estado Novo como mais antiga 
por representar uma família pobre, enquanto no $3 .^{\circ}$ ano e $4 .^{\circ}$ ano essas trocas se refletem entre as imagens $\mathrm{C}, \mathrm{D}$ e $\mathrm{E}$ e não só por considerarem a imagem E da Família do Estado Novo como mais antiga, mas também por trocas entre a C (Família dos Viscondes de Santarém) e a D (Família Burguesa).

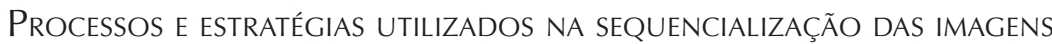

Procurámos analisar quais os processos e estratégias utilizados na sequencialização de imagens a partir das justificações apresentadas pelos alunos. Pediu-se para "pensarem alto" à medida que iam ordenando as imagens e depois de uma primeira proposta foram-lhes colocadas perguntas de acordo com essa ordenação e com as respostas que iam dando no sentido de justificarem a ordenação, sobretudo para justificarem por que razão Ihes parecia que umas eram mais ou menos antigas do que outras. Neste parâmetro, Processos e estratégias utilizados na sequencialização de imagens, identificámos seis categorias:Linguagem e vocabulário de tempo; Distinção temporal; Identificação de marcadores de mudança; Processos explicativos utilizados; Fontes de conhecimento; Suporte material da evidência histórica.

Nesta categoria, Linguagem e vocabulário de tempo associado ao sistema convencional, verificámos que a descrição qualitativa do tempo surge de forma persistente em todos os anos de escolaridade, embora sejam os alunos mais novos $\left(1 .^{\circ}\right.$ e $2 .^{\circ}$ anos) que a utilizam com maior frequência como indicativo de tempo e quando pretendem exprimir distâncias temporais usam as expressões: "há muito muito tempo"; "há muito tempo"; "não é tão antiga"; "é um bocadinho antiga". Utilizam com frequência o termo "velho" e "novo" associado à dimensão temporal. Os alunos a partir do final do $3 .^{\circ}$ ano utilizam termos de tempo qualitativo de uma forma mais objetiva: "um pouco mais recente"; "ainda é mais moderna". A referência ao sistema convencional de datação é pouco frequente antes do $4 .^{\circ}$ ano e só esporadicamente alguns alunos dos dois primeiros anos utilizam expressões associados a períodos históricos. No entanto, alguns alunos mesmo do $1 .{ }^{\circ}$ ano (embora poucos), mas sobretudo os alunos mais velhos, do $3^{\circ}$ e $4 .{ }^{\circ}$ anos e com maior frequência, usam expressões e vocabulário histórico em que associam as imagens a determinados períodos da História: "tempo dos dinossauros", "tempo dos piratas", "tempo dos reis", "tempo de Jesus", "tempo dos romanos", "tempo da escravatura", pré-históricos", 
"idade da pedra", "homens das cavernas" sem indicarem propriamente período históricos convencionais. Só no $4 .^{\circ}$ ano quando questionados é que os alunos indicam a localização em séculos para algumas das imagens, mas raramente o fazem de forma correta. A contagem do tempo a.C. e d. C. só no $4 .^{\circ}$ ano é referida. Comprovou-se que a datação e datas, pouco significado têm para os alunos antes do $3 .^{\circ}$ ano. Revelouse que a avaliação do intervalo de tempo entre as imagens é realizada maioritariamente de forma qualitativa, no entanto quer os do $2 .^{\circ}$ ano quer os do $4 .^{\circ}$ ano facilmente reconhecem entre que imagens se passou mais tempo e menos tempo.

Nesta categoria Distinção temporal pudemos verificar que em todos os anos de escolaridade os alunos estabelecem como estratégia o referirem-se a diferenças dicotómicas entre as imagens, reconhecendo todos os alunos qual a imagem mais antiga e a mais recente, no entanto o número e a complexidade das expressões dicotómicas vão aumentando. Também em todos os anos os alunos tendem a comparar as imagens com o presente, mas são os alunos do $1 .^{\circ}$ e $2 .^{\circ}$ ano que o fazem mais a nível descritivo. Comparam as imagens essencialmente com base em marcadores da cultura material, referindo-se ao que ainda não existia nesse tempo, revelando uma conceção de passado deficitário.

Uma outra estratégia usada principalmente pelos alunos no final do $2 .^{\circ}, 3 .^{\circ}$ e $4 .^{\circ}$ anos é o de compararem duas ou mais imagens com base nos marcadores da cultura material, refletindo a aprendizagem de leitura de imagens promovida em várias das implementações em sala de aula. Para a justificação do posicionamento das imagens os alunos procuram identificar marcadores da mudança ao nível da cultura material e vida quotidiana (vestuário, habitação, recheio da casa, progresso tecnológico) e indicadores económicos e sociais (rural/urbano; riqueza/pobreza e estatuto social). Os alunos no final do $2 .^{\circ}$ ano, $3 .^{\circ} \mathrm{e} 4 .^{\circ}$ anos procuram mais detalhes nas imagens ao nível dos marcadores da cultura material, revelando mais competência na leitura de imagens, e em produzir generalizações. O vestuário foi o marcador mais referido, seguido pelo da habitação, e o progresso tecnológico é salientado principalmente pelos alunos mais velhos. Em alguns alunos a ideia de pobreza surge como um elemento justificativo de antiguidade, e esporadicamente, alguns dos alunos associam a ruralidade à pobreza, principalmente os mais novos, o que justifica de certa forma as incorreções na sequencialização das imagens do meio, principalmente da imagem E (Família do Estado 
Novo) considerando que esta representa uma família pobre e por isso, temporalmente, mais antiga que a imagem D (família burguesa da classe média).

Assim no parâmetro, Processos explicativos e fontes do conhecimento histórico, pudemos constatar que os alunos utilizam vários processos para sequencializar as imagens, variando a sua frequência com o ano de escolaridade. Assim são as crianças mais novas que utilizam como estratégia para justificar a ordem das suas imagens a construção de contextos narrativos, o contarem uma história para explicar a sua sequência ou contar uma diferente para cada uma das imagens. Também, é sobretudo, os mais novos que menos dizem quando explicam a sua sequencialização, revelando dificuldades em explicar porque colocaram as imagens numa determinada sequência e muitas vezes limitam-se a descrever simplesmente o que veem na imagem ao nível dos marcadores da cultura material (vestuário, habitação, mobiliário, iluminação, objetos, etc.).

Outros alunos servem-se de uma outra estratégia a de recorrerem aos conhecimentos gerais que possuem adquiridos em vários contextos: livros, media, catequese, visitas, família, etc., aplicando esses conhecimentos à vida quotidiana no passado. No entanto, principalmente nos alunos do $1 .^{\circ}, 2 .^{\circ}$ e início do $3 .^{\circ}$ ano, por vezes esses conhecimentos não se revelam corretos levando-os a proceder a explicações pouco válidas. Gradualmente os alunos vão aplicando conhecimentos históricos adquiridos em vários contextos, mas é a partir do $4 .{ }^{\circ}$ ano que mais se torna evidente a aplicação desses conhecimentos nas justificações dadas à sequencialização das imagens, adquiridos principalmente em contexto escolar, com o estudo de História de Portugal, que se inicia nesse ano. Relativamente às imagens do meio da sequência os alunos revelam menos conhecimentos, porque estas representam períodos históricos não estudados no programa do $1 .^{\circ}$ ciclo.

A categoria, Suporte material da evidência, isto é, a qualidade da imagem, cor e tonalidade, é pouco utilizada pelos alunos para justificar a sequencialização das imagens e os poucos que o fazem usam-na conjugada com outras justificações.

IDEIAS SOBRE A MUDANÇA HISTÓRICA

Procurámos também perceber que ideias apresentam os alunos do nosso estudo acerca da mudança histórica a partir da análise cruzada e holística 
das questões da entrevista e em particular da questão 8 introduzida na $3 .^{a}$ entrevista no $2 .^{\circ}$ e $4 .^{\circ}$ anos: $O$ que é que achas que mudou ao longo do tempo? Porquê, o que possibilitou identificar várias tendências na forma de pensamento dos nossos alunos acerca da vida ao longo do tempo e responder às questões: Como percecionam a mudança histórica? Que indicadores convocam para explicar a mudança? O que terá contribuído para essa mudança? Qual o ritmo e a direção da mudança?

Para a análise das ideias dos nossos alunos acerca da mudança histórica partimos dos três tipos de tendências identificadas em Barton (2001):

- ideias de progresso e mudança;

- ideias de mudança por questões individuais ou por fatores sociais;

- ideias de evolução e diversidade na mudança.

Sentimos, no entanto, necessidade de proceder à construção de uma categorização mais adequada às ideias propostas pelos alunos no nosso estudo já que se tratava de alunos de idades entre os 6 e os 10 anos. Assim identificaram-se as duas categorias seguintes:

- ideias de evolução da mudança com base no progresso linear;

- ideias de evolução da mudança com base na diversidade da mudança.

Em geral pudemos constatar que os alunos de todos os anos de escolaridade tendem a pensar mais na mudança ao longo do tempo como evolutiva de forma linear (progresso linear), do que como mudança numa perspetiva de diversidade, mesmo quando ordenam as suas imagens corretamente. Defendem uma melhoria contínua resultando do progresso tecnológico, material, económico, social e intelectual ao longo dos tempos. Os alunos tendem a usar expressões que revelam uma melhoria contínua "é melhor", "já tem mais coisas", "já tinham", "já estão mais evoluídos", "mais modernos", "mais avançados", associadas a vários marcadores da cultura material: vestuário, habitação, objetos, tecnológico, etc. Os alunos embora reconheçam diferenças entre o passado e o presente, identificam situações de simultaneidade e de permanência.

A maioria dos alunos, principalmente nos primeiros anos de escolaridade ( $1 .^{\circ}$ e $2 .^{\circ}$ anos) consideram que a mudança ocorre numa sequência progressiva ao longo do tempo e veem o passado como deficitário ao compará-lo com o presente, usando frequentemente 
expressões, "ainda não tinham", "ainda não havia", "não usavam". De certa forma os alunos que expressaram ideias de mudança relacionadas com progresso linear refletiu-se no modo como ordenaram as suas imagens, o que terá contribuído para que um número bastante significativo de alunos dos vários anos tendesse a considerar a imagem do Estado Novo como mais antiga por serem mais pobres. Surge associado a esta conceção de mudança a ideia de passado como tecnologicamente deficitário, indicando diferenças ao nível da cultura material, pior ou melhor vestuário, habitação, etc. e terem mais e melhor não só em quantidade como em qualidade.

Em relação à conceção de mudança com base na diversidade esta surge no final do $1 .{ }^{\circ}$ ano em alguns alunos que tendem a valorizar a especificidade e diferenças ao longo dos tempos, mas é especialmente a partir do $2 .^{\circ}$ ano que um maior número de alunos indica diferenças entre as imagens com base em marcadores da cultura material, social e económica. Os alunos tendem a usar expressões que revelam mudança, diferença: "é diferente", " mudou", "não eram assim como as de agora", "já usavam", "antes usavam ...", "ainda tem", "ainda se usa", associados a vários marcadores da cultura material, vestuário, habitação, objetos, tecnológico, etc. No entanto são poucos os alunos do $4 .^{\circ}$ ano que continuam a pensar o passado como deficitário comparado com o presente, mas reconhecem características próprias de uma época.

Os do $3 .^{\circ}$ e $4 .^{\circ}$ anos são mais específicos em referir o que mudou a nível da cultura material, mas também a nível social, cultural e político. No 3. ${ }^{\circ}$ ano há já alunos que reconhecem mudanças na mentalidade e nos comportamentos e da permanência de determinadas práticas que se mantém na atualidade. Esta conceção é ainda mais evidente no $4 .^{\circ}$ ano quando reconhecem que a evolução integra diversidade de situações podendo coexistir numa determinada época realidades bem diferentes. No final do $3 .^{\circ}$ ano dois alunos reconhecem que a mudança histórica pode ter vários ritmos, uns mais lentos, associados a mudanças de mentalidade, da sociedade e dos sistemas políticos e outras mais rápidas, associadas a ruturas como por exemplo revoluções (caso do 25 de abril de 1974).Para a Bernardete no início do $3 .^{\circ}$ ano a mudança de mentalidade e da evolução nos hábitos e costumes é um indicador importante de evolução da mudança e que perdurou durante muito tempo, sendo uma mudança lenta e recente: As senhoras não podiam usar calças, só saias e as roupas eram antigas. Também a Anabela no final do $3 .^{\circ}$ ano reconhece que a mudança 
de mentalidade, ao nível da condição feminina, dos seus comportamentos e hábitos se processou a um ritmo lento e neste século, permanecendo certos hábitos: A minha avó ainda ela, na vida dela, ela nunca usou calças. Aqui atrás os seres femininos está tudo com saias.Apesar de vários alunos pensar na mudança como diversidade e com diferentes ritmos, a maioria dos alunos continuam a pensar na evolução histórica de forma linear e progressiva.

\section{Conclusões}

A partir deste estudo comprovou-se que os alunos revelam capacidade em ordenarem imagens de épocas distanciadas no tempo e a sua capacidade de argumentação e justificação torna-se gradualmente mais complexa e elaborada, estabelecendo relações causais, reconhecendo mudanças e continuidades ao longo do tempo, inicialmente numa perspetiva linear de progresso, gradualmente substituída por uma conceção de mudança mais ampla, entendida como diversidade, progresso, continuidade, simultaneidade ou até mesmo regressão, reflexo do trabalho realizado ao longo deste projeto.

A linguagem de tempo qualitativo "“muito antigo", "de há muito tempo", "velho", "moderno", "recente", surge de forma persistente em todos os anos de escolaridade, substituída gradualmente pela utilização de vocabulário de tempo associado ao sistema convencional de medição do tempo, relacionado com os vários subsistemas de medição do tempo, o tempo do calendário e o tempo histórico. Só esporadicamente alguns alunos, quase exclusivamente os do $4 .^{\circ}$ ano utilizam terminologia referente a períodos históricos associados às imagens, reconhecendo a época histórica em que se poderia situar cronologicamente (PréHistória; do tempo de Jesus; Idade Média; Época dos Descobrimentos; Estado Novo, 25 de Abril) resultado de uma aprendizagem formal de História de Portugal nesse ano. Este estudo permitiu confirmar o que outros autores (Barton e Levstik, 1996; Hoodless, 1998, Barton, 2002) constataram em relação ao conceito de duração, a dificuldade dos alunos em compreender a duração/intervalo de tempo e calcular a distância antes do $3 .^{\circ}$ ano (8-9 anos), pois as crianças sentem mais dificuldades na utilização abstrata de datas e na distância temporal, pois implica cálculo e medição, associado ao raciocínio matemático. Para a medição 
das distâncias temporais os alunos fazem-no indiretamente através de termos e expressões que revelam diferentes graus de distância temporal como por exemplo: "há muito muito tempo", "há muito tempo", "é muito antiga", "a mais antiga", "muito antiga"; "muito velha", "não é tão antiga", "e esta também é antiga ... ", "é um bocadinho antiga", "um pouco mais recente", "está próxima de nós".

Os resultados deste estudo permitem concluir que estes alunos que participaram neste projeto desenvolveram competências temporais, ao nível cronológico (sequencialização e datação) e uma complexificação do raciocínio temporal, assim como alterações nas suas conceções sobre mudança. Pudemos constatar que os alunos revelaram mais conhecimentos históricos do que pensávamos que possuíam, adquiridos em contextos formais e informais, como na família, na catequese, em livros, nos media, em visitas a museus, cidades ou monumentos e mobilizam-nos quando solicitados, aplicando-os nos argumentos explicativos dos seus raciocínios sobre temporalidade quando observavam as imagens. Podemos afirmar que a compreensão temporal e a compreensão histórica se desenvolvem de forma gradual de acordo com idade, no entanto esta não é um fator determinante, pois os contextos de aprendizagem e estratégias adequadas podem acelerar o desenvolvimento da compreensão temporal e histórica, como este estudo permitiu demonstrar. É nos primeiros anos de escolaridade que se deve promover nos alunos estruturas cognitivas essenciais ao nível do pensamento histórico e temporal, indispensáveis para uma melhor aprendizagem e compreensão da história, ao longo do percurso escolar.

\section{Referências}

Asensio, M., Carretero, M. \& Pozo, J.(1989). La comprensión del tiempo histórico. In M. Carretero, J. I. Pozo \& M. Asensio (Ed.) La enseñanza de las Ciencias Sociales (pp.103139). Madrid: Visor Distribuciones.

Ashby, R. \& Lee, P. (1987). Children's concepts of empathy and understanding in history. In C. Portal (Ed.), The history curriculum for teacher (pp. 62-88). London: The Falmer Press.

Barca, I. (2015). 'History and temporal orientation: The views of Portuguese-speaking students', in A. Chapman \& A. Wilschut (Eds.),Joined-up history: New Directions in History Education Research (pp. 13-35). Charlotte, NC: Information Age Publishing. 
O desenvolvimento da compreensão do tempo e do tempo histórica nas crianças: um estudo de caso com alunos portugueses de primária (1. $\left.{ }^{\circ} \mathrm{CEB}\right)$

GLÓRIA SOLÉ

Barton, K. C. \& Levstik, L. S. (1996). "Back when God was around and everything": Elementary children's understanding of historical time. American Educational Research Journal, 33 (2), 419-454.

Barton, K. C. (2001). A socialcultural perspective on children's understanding of historical change: comparative findings from Northern Ireland and the United States. American Education Research Journal, 38(4), 881-913.

Barton, K. C. (2002) "Oh, that's a Tricky Piece!": Children Mediated Action, and the Tools of Historical Time. TheElementary School Journal, 37(1), 89-106.

Barton, K. C. (2008). Visualizing time. In L. S. Levstik \& K. C. Barton (Eds), Researching History Education - Theory, Method and Context (pp. 61-70). New York: Routledge.

Bruner, J. (1960). The Process of Education. Cambridge, MA: Harvard University Press.

Cooper, H. (1991). Young Children's Thinking in History. Unpublished PhD Thesis. Institute of Education. London: London University.

Cooper, H. (1995). History in the Early Years: Teaching and Learning in the first three Years of School. London: Routledge.

Domínguez, J. (2015). Pensamiento histórico y evaluación de competencias. Barcelona: Editorial GRAÓ.

Downey, M. T. \& Levstik, L. S. (1991). Teaching and learning history. In J. P. Shaver (Ed.), Handbook of research on social studies teaching and learning(pp. 400-410). New York: Macmillan.

Erickson, F. (1986). Qualitive Methods in Research on Teaching. In M. Wittrock (Ed.),

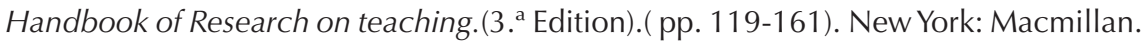

Forrest, M. \& Harnett, P. (1996). Curriculum Bank History, Key Stage Two History: 1. Leamington Spa, Scholastic.

Foster, S. J.; Hoge, J. D. e Rosch, R. H. (1999). Thinking aloud about history:children's and adolescents' responses to historical photographs. Theory and Research in Social Education, 27 (2): 179-214.

Fraisse, P. (1982). The adaptation of the child to time. In W. Friedman (Ed), The Developmental Psycology of Time (pp. 113-140). London: Academic Press.

Friedman, W. J. (1982). Conventional time concepts and children's structuring of time. In W. Friedman (Ed.), The Developmental Psychology of Time (pp. 171- 208). London: Academic Press.

Groot-Reuvekamp, M. , Boxtel, C., Ros, A. e Harnett, P.(2014). The understanding of historical time in the primary history curriculum in England and the Netherlands, Journal of Curriculum Studies.

Disponível : http://dx.doi.org/10.1080/00220272.2013.869837 [acedido a 17/09/17].

Harner, L. (1982). Talking about the Past and the Future. In W. Friedman (Ed.), The Developmental Psychology of Time (141-169). London: AcademicPress.

Harnett, P. (1993). Identifying Progression in Children's Understanding: The use of visual materials to assess primary school children's learning in history. Cambridge Journal of Education, 23 (2), 137-154.

Hodkinson, A. (2003). Children's developing conceptions of historical time: analysing approaches to teaching, learning and research, unpublished PhD thesis, UK, Edge Hill: University of Lancaster. 
O desenvolvimento da compreensão do tempo e do tempo histórica nas crianças: um estudo de caso com alunos portugueses de primária (1. $\left.{ }^{\circ} \mathrm{CEB}\right)$

GLÓRIA SOLÉ

Hoge, J. D. \& Foster, S. J. (2002). It's about time: Students' Understanding of chronology, Change, and development in a Century of Historical Photographs. Annual Meeting of The American Education Research Association, New Orleans: Louisiana.

Jahoda, G. (1963). Children's concepts of time and history. Educational Review15(287), 87-104.

Lee, P. \& Ashby, R. (1987). Discussing the evidence. Teaching History, 48, 13-17.

Levsik, L. \& Papas, C. (1987). Exploring the development of historical understanding. Journal of Research and Development in Education, 21 (1), 1-15.

Levstik, L. \& Barton, K. (1996). 'They still use some of their past': historical salience in elementary children's chronological thinking. Journal of Curriculum Studies,28 (5), 531-576.

Lomas, T. (1990). Teaching and Assessing Historical Understanding. London: Historical Association.

Oakden, E. C. \& Sturt, M. (1922). The development of the knowledge of time in children. British Journal of Psychology, 12 (4), 309-355.

Pagès, J. \& Santisteban, A. ( 2010). La enseñanza y el aprendizaje del tiempo histórico en la educación primaria. Cad. Cedes, Campinas, 30(82), 281-309.

Pagès, J. (2009). Conciencia y tiempo histórico. Perspectiva escolar, 332, 2-8.

Patriarca, L. A. \& Alleman, J. (1987). Studying time: A cognitive approach. Social Education, 51 (4), 273-277.

Piaget, J. (1946). A noção de tempo na criança. Rio de Janeiro: Editora Record.

Rüsen, J. (2007). Making sense of time: Toward a universal typology of conceptual foundations os historical consciousness. In Jörn Rüsen (Ed.). Time and History: The variety of cultures (pp. 7-18). New York: Berghahn Books.

Rüsen, J. (2016). O que é a cultura? Reflexões sobre uma nova maneira de abordar a História. Maria Auxiliadora Schmidt e Estevão R. Martins (Org.). Jörn Rüsen - Contribuições para uma teoria da didática da História (pp.54-81). Curitiba: W.A.Editores.

Sacristán, M. (2012). Recursos y técnicas para la comprensión del tiempo en educación primaria. Tese de Mestrado. Valladolid:Universidad de Valladolid.

Shemilt, D. (1980). History 13-16 evaluation Study. Edinburgh: Holmes McDougall.

Shemilt, D. (1987). Adolescent ideas about evidence and methodology in history. In C. Portal (Ed.), The history curriculum for teachers (pp. 39-61). London: The Falmer Press.

Solé, G. (2009). A História no $1{ }^{\circ}$ Ciclo do ensino básico: a concepção do tempo e a compreensão histórica das crianças e os contextos para o seu desenvolvimento. Tese de Doutoramento não publicada. Braga: Universidade do Minho.

Stow, W. \& Haydn, T. (2004). Issues in the teaching of chronology, In J. Artur and R. Phillips, Issues in History Teaching (pp.83-97). London: Routledge Falmer .

Strauss, A. \& Corbin, J. (1990). Basics of qualitative research. Grounded theory, procedures and techniques. Newbury Park: Sage Publications.

Thornton, S. J. \& Vukelich, R. (1988). Effects of children's understanding of time concepts on historical understanding. Theory and Research in Social Education, 17 (1), 69-82.

Vygotsky, L.S. (1962). Thought and Language. Cambridge, MA: MIT Press. 
O desenvolvimento da compreensão do tempo e do tempo histórica nas crianças: um estudo de caso com alunos portugueses de primária (1. $\left.{ }^{\circ} \mathrm{CEB}\right)$

GLÓRIA SOLÉ

West, J. (1981). Primary school children's perception of authenticity and time in historical narrative pictures. Teaching History, 24, 8-10.

Wilschut, A. (2010). A forgotten key concept? Time in teaching and learning history. Comunicação apresentada no 21st International Congress of Historical Sciences, Amesterdam. Disponível: http://members.casema.nl/wilschut/forgottenkeyconcept. pdf [acedido: 1-09-17].

Wineburg, S. (1996). The psychology of learning an teaching history. In D. C. Berliner \& R. C. Calfee (Eds), Handbook of education psychology (pp.423-437). New York: Macmillan.

Wood, S. (1995). Development an understanding of time-sequencing issues. Teaching History, 79, 11-14.

Yin, R. K. (2003). Case Study Research: Design an Methodology (2.nd ed.), London: Sage Publications. 



\section{Anexo A. Imagens usadas nas entrevistas semi-estruturadas para a sequencialização temporal}

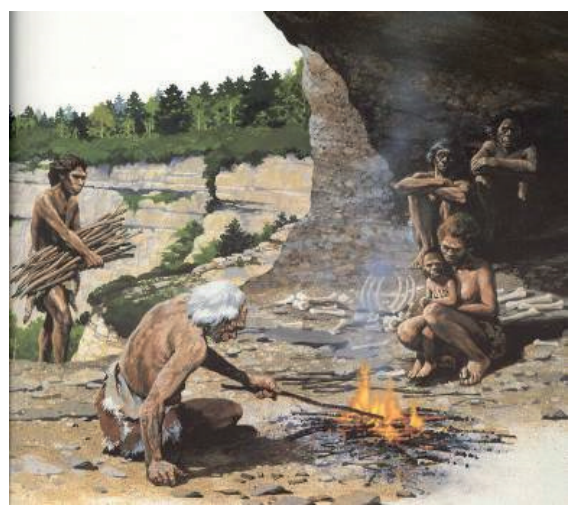

A) Família da Pré-história

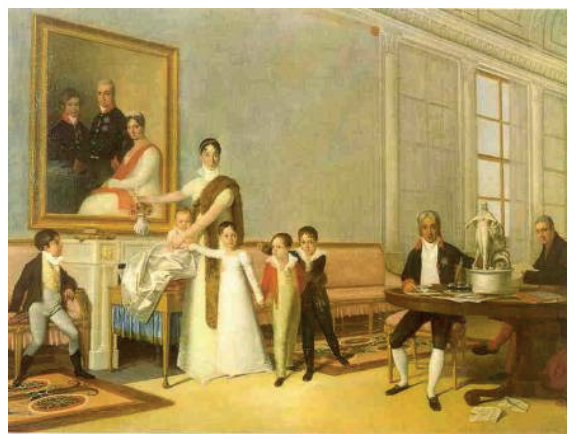

C) Pintura de uma família da nobreza (1816)

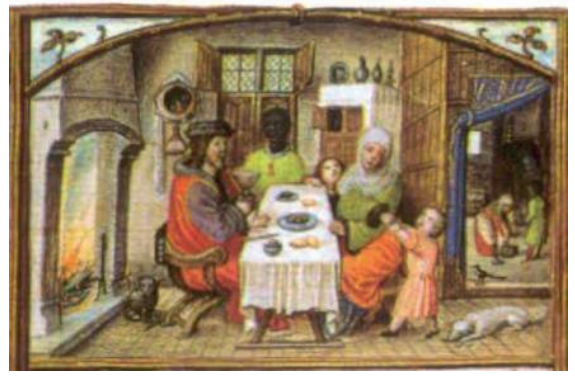

B) Iluminura de família do século

$\mathrm{XVI}$

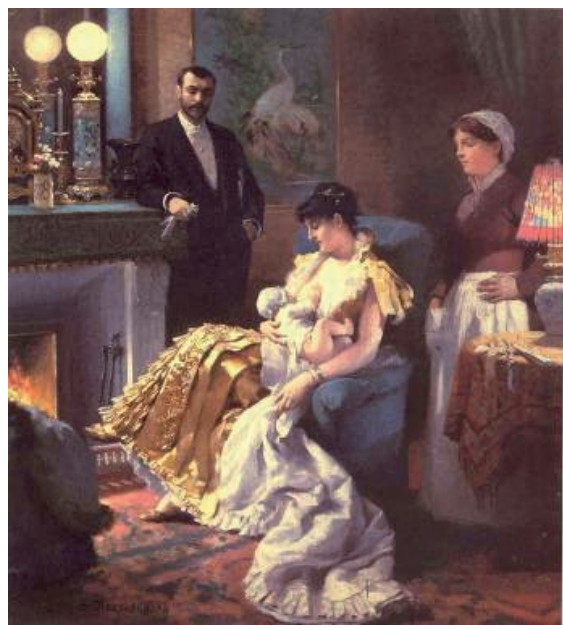

D) ou C) Pintura de uma família burguesa (1886); 


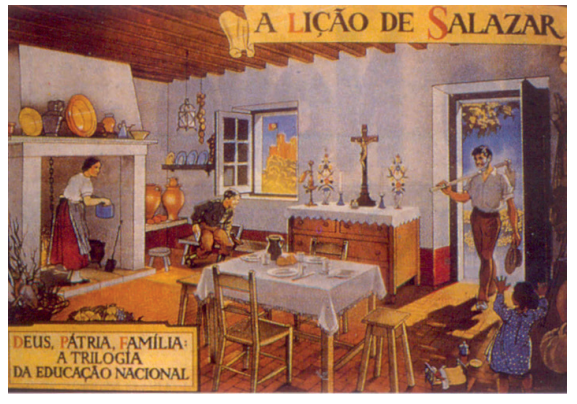

E) ou D) Poster de propaganda do Estado Novo com uma família rural (1933-49)

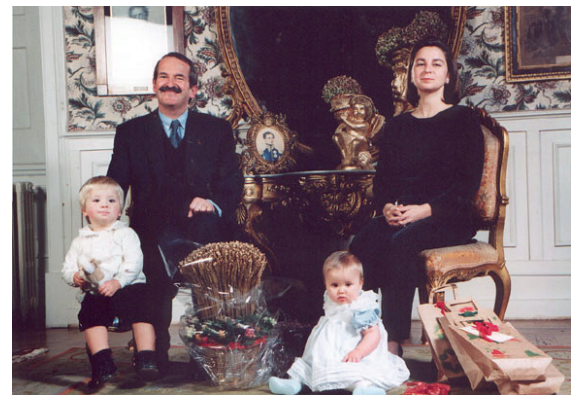

F) ou E) Família dos Duques de Bragança (1999)

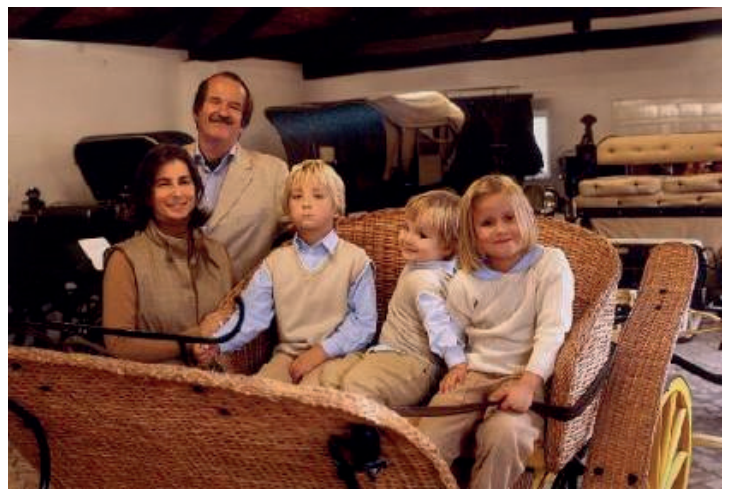

G) ou F) Família dos Duques de Bragança (2003). 